\title{
Effect of well-dispersed surface-modified silica nanoparticles on crystallization behavior of poly (lactic acid) under compressed carbon dioxide
}

\author{
K. Sarikhani ${ }^{\text {a, b }}$, R. Nasseri ${ }^{\text {a }}$, V. Lotocki ${ }^{\text {c }}$, R.B. Thompson ${ }^{\text {b, d }}$, C.B. Park ${ }^{\text {e }}$, P. Chen ${ }^{\text {a, b, * }}$ \\ ${ }^{\text {a }}$ Department of Chemical Engineering, University of Waterloo, Waterloo, Ontario, N2L 3G1, Canada \\ ${ }^{\mathrm{b}}$ Waterloo Institute for Nanotechnology, University of Waterloo, Waterloo, Ontario, N2L 3G1, Canada \\ ${ }^{c}$ Department of Chemistry, University of Waterloo, Waterloo, Ontario, N2L 3G1, Canada \\ d Department of Physics and Astronomy, University of Waterloo, Waterloo, Ontario, N2L 3G1, Canada \\ e Microcellular Plastics Manufacturing Laboratory, Department of Mechanical and Industrial Engineering, University of Toronto, Toronto, Ontario, M5S 3G8, \\ Canada
}

\section{A R T I C L E I N F O}

\section{Article history:}

Received 23 February 2016

Received in revised form

29 May 2016

Accepted 7 June 2016

Available online 9 June 2016

\section{Keywords:}

Poly (lactic acid)

Crystallization

Silica

\begin{abstract}
A B S T R A C T
In this work, the crystallization behavior of poly (lactic acid) (PLA)/amine-modified silica nanocomposites at different loadings of amine-modified silica (1, 2, and $8 \mathrm{wt} \%$ ) under isothermal, nonisothermal, and isothermal under compressed $\mathrm{CO}_{2}$ is studied. A significant improvement in crystallization rate was observed after introduction of the nanoparticles. A modified Hoffman-Lauritzen nucleation theory was utilized to explain the facilitation and acceleration of the crystallization process of nanocomposites with introducing the surface energy of the nanoparticles and interfacial energy between polymer/nanoparticle into the rate equation. After incorporation of the nanoparticles, three-dimensional spherulites formed sporadically in the PLA matrix based on the prediction of the Avrami exponents of the nanocomposites. High-pressure DSC results also showed an increase in the crystallization rate at 15 bar compared with the atmospheric pressure condition. However, an increase in pressure up to 21 bar had no significant effect on the crystallization rate. The PLA nanocomposites with lower molecular weights and D-content also showed a significant increase in the crystallization rate but with no change in the crystallization mechanism.
\end{abstract}

() 2016 Elsevier Ltd. All rights reserved.

\section{Introduction}

Poly (lactic acid) (PLA) is an aliphatic polyester composed of lactic acid (2-hydroxy propionic acid) building blocks derived from renewable plant sources. As a biodegradable and compostable thermoplastic, PLA is a promising sustainable material which can contribute to resolving the environmental issues such as waste disposal [1,2]. Furthermore, in addition to its environmentally benign characteristics, the biodegradable and biocompatible characteristics of PLA has made this polymer an ideal material for biomedical applications and food packaging products [3-6]. On the other hand, the mechanical properties such as appropriate modulus and physical properties like clarity of PLA make it a prospective

\footnotetext{
* Corresponding author. Department of Chemical Engineering, University of Waterloo, Waterloo, Ontario, N2L 3G1, Canada.
}

E-mail address: p4chen@uwaterloo.ca (P. Chen). candidate to replace petroleum-based synthetic polymers [7].

One promising application for PLA is being used as polymeric foam materials. Polymeric foams are interesting lightweight materials with proper mechanical, energy absorbing, and insulation properties [8]. In addition to the general advantages of foam materials, PLA foams have the biodegradable and biocompatible characteristics, which make them an attractive replacement for commodity foam products for addressing global waste disposal concerns [4]. Despite numerous valuable advances, production of PLA foams with uniform morphology using physical blowing agents is still challenging [9]. One barrier for PLA foam production is its low melt-strength. Various methods, such as introducing chain extenders [10], branching the chains [2,11], and compounding with various fillers and additives (micro and nanoparticles) [12-14] have been used to address the low melt strength of PLA. In addition to melt strength, improvement in crystallization behavior and crystallinity can further improve the mechanical properties of PLA [15-19]. 
Nanoparticles can be used to improve PLA foamability through the improvement in crystallization, melt strength, and reduction of interfacial tension of the PLA system. It has been shown that both carbon dioxide $\left(\mathrm{CO}_{2}\right)$ dissolution $[20,21]$ and the addition of nanoparticles [22] can reduce the interfacial tension of PLA $-\mathrm{CO}_{2}$ mixtures. In addition, nanoparticles can serve as nucleating agents in the nucleation step of foaming $[23,24]$. Moreover, in nucleation step in crystallization a pre-existing surface causes the reduction in free energy barrier against the primary crystallization nucleation. It was shown that in polypropylene composites filled with hydrophobic fumed silica (modified with dimethyldichlorosilane), the nucleus size for crystallization decreases with incorporation of foreign surfaces as result of less resistance in creation of interface between the crystal and substrate compared with that of free polymer $[25,26]$. This would be an important factor in improvement of PLA crystallization with very slow kinetics.

In this paper, the crystallization behavior of PLA/silica nanocomposites at different loadings of silica in both isothermal and non-isothermal conditions is studied. Prior to crystallization analysis, a proper surface modification of the silica nanoparticles is selected to satisfy the need for a well-dispersed nanocomposites, higher-absorption of $\mathrm{CO}_{2}$, and a faster crystallization rate. Surface energy of the nanoparticles and interfacial energy between polymer/nanoparticle at high temperatures are approximated in a modified Hoffman-Lauritzen nucleation theory to explain the acceleration of the crystallization process in the presence of nanoparticles. In order to consider the crystallization improvement for foaming processes, isothermal crystallization under compressed $\mathrm{CO}_{2}$ is also investigated. The heterogeneous nucleation provided by nucleation agents such as silica nanoparticles improves the crystallization rate at high temperatures when there is less driving force for homogeneous nucleation. In addition to the role as a blowing agent in foaming, the effect of carbon dioxide as a plasticizer on crystallization is expected to be more dominant at lower temperatures where higher chain mobility is required for crystallization. That is the reason why the effect of $\mathrm{CO}_{2}$ has been studied at a low and narrow crystallization temperature window. Combining nucleation (through heterogeneous nucleation of surface-modified silica nanoparticles) and plasticization (via dissolution of carbon dioxide in polymer matrices) is expected to increase the crystallization rate and broaden the crystallization temperature window in the foaming process of PLA.

\section{Experimental}

\subsection{Materials}

Three different grades of polylactic acid (PLA) under trade names of 2002D, 3001D, and 4032D were kindly provided by NatureWorks Inc. The molecular weight and D-content of the PLA grades are listed in Table 1. Chromatographic grade carbon dioxide with a purity of $99.98 \%$ was purchased from Linde Gas for highpressure DSC measurements. Tetraethyl orthosilicate (TEOSSigma-Aldrich) and ammonium hydroxide (28-30\% solution Sigma-Aldrich), were used for synthesis and (3-Aminopropyl)

Table 1

Molecular weight and D-content of PLA materials in the current work.

\begin{tabular}{lll}
\hline PLA trade name & Number average molecular weight $(\mathrm{kg} / \mathrm{mol})$ & D-content $(\%)$ \\
\hline PLA 2002D & 100 & 4.5 \\
PLA 3001D & 72 & 1.4 \\
PLA 4032D & 58 & 1.8 \\
\hline
\end{tabular}

triethoxysilane (APTES) (99\% - Sigma-Aldrich) was used for surface modification of the silica nanoparticles. The deionized water was from a Millipore Milli-Q system with $18.2 \mathrm{M} \Omega$ resistivity.

\subsection{Synthesis, surface modification, and compounding of silica nanoparticles}

The synthesis, surface modification, and characterization of the silica nanoparticles can be found more in detail in our previous work [22]. Briefly, the nanoparticles were synthesized using the Stöber method [27] and then they were separated, washed, and dried in an oven. The (3-aminopropyl) trimethoxysilane (APTES) was used for surface modification of the nanoparticles [22,28,29]. Following the surface modification of the silica nanoparticles, they were dispersed in PLA via melt mixing utilizing a lab scale twinscrew extruder (Haake Mini Lab Rheomex CTW5). The mixing temperature $\left(180^{\circ} \mathrm{C}\right)$, speed $(150 \mathrm{rpm})$ and the mixing time were chosen based on some preliminary thermal and mixing experiments to achieve a high level of mixing and also prevent polymer degradation.

\subsection{Characterization}

Morphology and dispersion of the nanoparticles in PLA was obtained using field emission scanning electron microscopy (FESEM) (Ultra, Zeiss). Thermal analysis was performed using a DSC2000 (TA Instruments) at atmospheric pressure and a DSC 204 $\mathrm{HP}$ (NETZSCH, Germany) at high pressures of $\mathrm{CO}_{2}$. The crystal structure of PLA was characterized using X-ray diffraction (XRD) techniques (Bruker) with $\mathrm{Cu}-\mathrm{K} \alpha$ radiation with wavelength of $1.5406 \AA$ Å operating at $40 \mathrm{kV}$ and $30 \mathrm{~mA}$.

\subsection{Isothermal analysis and kinetics of crystallization}

Calorimetry was used to study the kinetics of crystallization. The samples were heated from room temperature to $200{ }^{\circ} \mathrm{C}$ at the rate of $10{ }^{\circ} \mathrm{C} / \mathrm{min}$ then equilibrated at that temperature for $5 \mathrm{~min}$ to remove all previous thermal and stress histories. The samples were cooled to the isothermal temperature at the rate of $30^{\circ} \mathrm{C} / \mathrm{min}$ and then were equilibrated at the isothermal temperature, and heat flow was measured as a function of time for $60 \mathrm{~min}$ or until crystallization was completed. The heat flow data was converted to a fraction relative to the final crystallinity level, and the results were plotted as a function of time to obtain Avrami plots. The Avrami equation (1) was used to analyze the crystallization kinetics of the samples $[30,31]$ :

$x(t)=1-e^{(-k t)^{n}}$

where $x(t)$ is the relative crystallinity at time $t, k$ is a kinetic rate constant and $n$ is the Avrami exponent. The double-log Avrami plots of $\ln (-\ln (1-x(t)))$ versus $\ln (t)$ were plotted to obtain the Avrami exponent, $\mathrm{n}$, and the crystallization kinetic constant, $\mathrm{k}$.

The Avrami exponent normally has a value, which lies between 2 and 4 for polymer crystallization, and it determines the mechanism of nucleation (homogeneous or heterogeneous and simultaneous or sporadic), the dimensionality of crystal growth (two or three dimensional) and growth mechanism (linear or diffusion controlled) of the system. The higher Avrami exponents are attributed to sporadic (or combination of sporadic and simultaneous) nucleation with three-dimensional spherulitic growth. On the other hand, the lower exponent values represent instantaneous (accompanied with some sporadic) nucleation with twodimensional growth [7,32]. Another important piece of information obtained from isothermal crystallization is the crystallization 
half-time $\left(t_{1 / 2}\right)$ which is defined as the time it takes to reach $50 \%$ of crystallization. The reciprocal of $t_{1 / 2}$ is a measure of crystallization kinetics and is defined as the crystallization rate $(G)$. It should be mentioned that due to the simplifications in derivation of the Avrami equation, it is not necessarily accurate to draw a definite conclusion on the microscopic mechanism of the crystal growth without morphological information [33].

\section{Results and discussion}

\subsection{Calculation of the surface energy and its effect on dispersion of nanoparticles and crystallization of PLA}

The size, uniformity, and surface modification of silica nanoparticles has been already examined with SEM, TEM, DLS, and FTIR, and the results were presented in our previous work [22]. The silica nanoparticles were spherical and monodispersed with a z-average size of $100 \mathrm{~nm}$. Fig. 1 shows the SEM image of the cryogenically fractured surface of PLA 2 wt\% nanocomposite at two different magnifications. The surface modified silica nanoparticles show excellent distribution and good dispersion inside the polymeric matrices, and the individual spherical particles and small aggregates of two to three particles are uniformly distributed inside the PLA matrices.

The surfaces of silica nanoparticles are modified with amine containing silanes for the following reasons: first of all, it provides a surface with lower energy. The surface-modified silica contributes to better dispersion of the particles in the matrices and the work of adhesion will be higher in the case of a proper selection of surface modification. Secondly, the amine group can improve the adsorption of $\mathrm{CO}_{2}$ on the surface of the silica particles [34] via induced interaction between the basic amines functional groups on the surface of modified particles and the acidic $\mathrm{CO}_{2}$ molecules to form ammonium carbamates in anhydrous conditions [35]. Thirdly, the amphiphilic characteristic of the surface-modified nanoparticles, and their affinity towards $\mathrm{CO}_{2}$, promotes their irreversible adsorption to the polymer $/ \mathrm{CO}_{2}$ interface [22]. On the other hand, the three-phase contact angle between nanoparticle/polymer $/ \mathrm{CO}_{2}$ is a determining factor in the free energy barrier for heterogeneous nucleation $\left(\mathrm{W}_{\text {het }}\right)$ in polymer foams $[36,37]$ :
$W_{\text {het }}=\frac{16 \pi \gamma_{l}^{3} F}{3\left(P_{\text {bubble }}-P_{\text {system }}\right)}=W_{\text {homo }} F$

where $\mathrm{F}$ is the energy reduction factor for heterogeneous nucleation and $\gamma_{1}$ is the liquid (melt) surface tension, $\mathrm{P}$ bubble is the pressure inside the critical bubble, and $\mathrm{P}$ system is the system pressure. The factor depends on the geometry of the nucleating site and it can be a function of $\theta[38]$ :

$F(\theta)=\frac{2+3 \cos \theta-\cos ^{3} \theta}{4}$

where $\theta$ is the three - phase contact angle between nanoparticle (solid)/polymer (liquid) $/ \mathrm{CO}_{2}$ (gas) from Young's equation:

$\gamma_{l} \cos \theta=\gamma_{s}-\gamma_{s l}$

where $\gamma_{1}$ is the liquid-vapor surface tension, $\gamma_{s}$ is the solid-vapor surface tension, and $\gamma_{s l}$ is the solid-liquid interfacial tension Equation ( 3 ) shows that an increase in $\theta$ leads to a decrease in $\mathrm{F}$ and consequently $W_{\text {het. }}$ Considering Young's equation, in order to have a larger $\theta$ one can either decreases $\gamma_{s}$ or increases $\gamma_{s \mathrm{~s}}$. On the other hand, due to low surface energy of polymer melts, a low-energy solid-gas interface is required to minimize the interfacial tension between the dispersed particles and the polymer matrix for improvement of particles wettability, better dispersion of particles and a uniform composite. Moreover, in foams stabilized with nanoparticles it is required for the particles to have the ability to adsorb to the interface of the two phases. Partial wetting of the solid particles by the two phases is one of the key requirements for their adsorption at the interface [39]. In polymer foams, surface modification of silica with $\mathrm{CO}_{2}$-philic functional groups is shown to promote nanoparticles' adsorption to the polymer-carbon dioxide interface with high binding energies to the interface [22]. As a result of all this, surface modification of silica nanoparticles in the current study is a key step to both reduce the energy barrier for nucleation in foaming and to provide a low surface energy particle for better dispersion.

Contact angle measurements of silicon wafers and silicon modified with APTES at room and high temperatures are used to

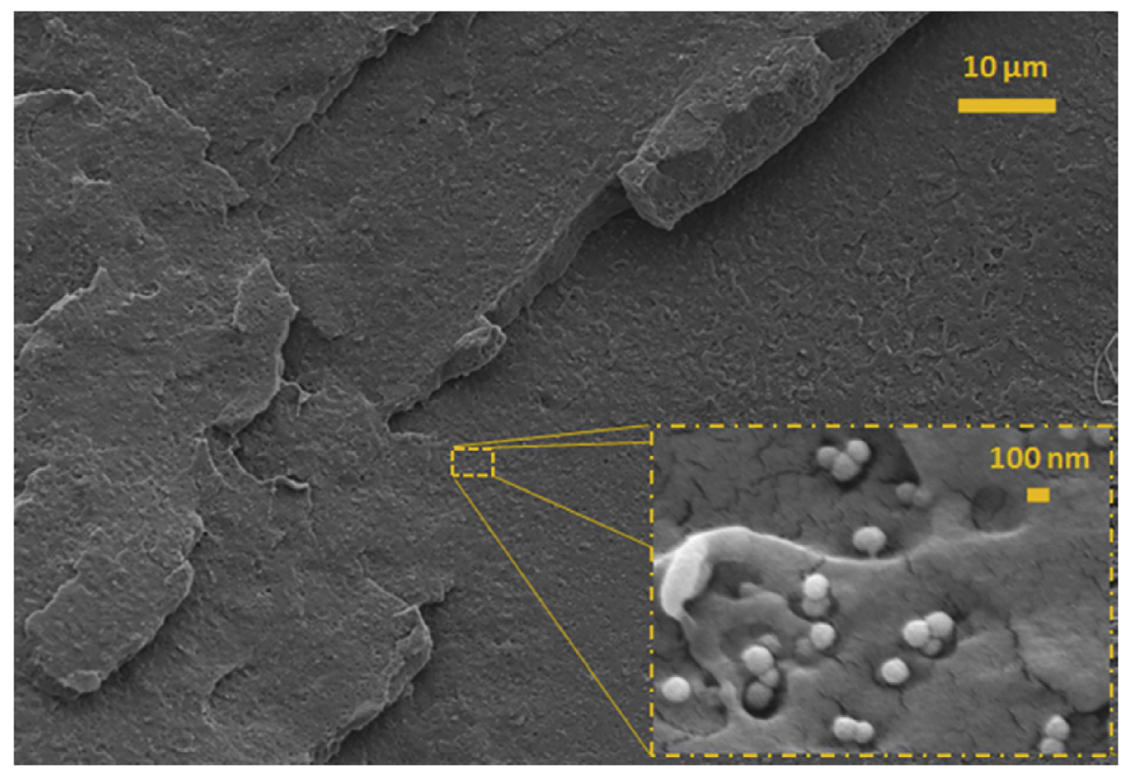

Fig. 1. SEM image of 2 wt\% PLA nanocomposite fractured in liquid nitrogen. The large image is at $1 \mathrm{k}$ and the inset is at $50 \mathrm{k}$ magnification. 
Table 2

Surface energy calculation of silicon and silicon-APTES and corresponding interfacial tension with PLA at high temperatures.

\begin{tabular}{|c|c|c|c|c|c|c|c|}
\hline \multirow[t]{2}{*}{ Temperature } & \multirow{2}{*}{$\frac{\text { PLA }}{\text { Surface tension }}$} & \multicolumn{3}{|l|}{ Silicon } & \multicolumn{3}{|l|}{ Silicon APTES } \\
\hline & & Contact angle & Surface energy (Neumann) & Interfacial tension & Contact angle & Surface energy (Neumann) & Interfacial tension \\
\hline${ }^{\circ} \mathrm{C}$ & $\left(\mathrm{mJ} / \mathrm{m}^{2}\right)$ & $\overline{\left({ }^{\circ}\right)}$ & $\left(\mathrm{mJ} / \mathrm{m}^{2}\right)$ & $\left(\mathrm{mJ} / \mathrm{m}^{2}\right)$ & $\overline{\left({ }^{\circ}\right)}$ & $\left(\mathrm{mJ} / \mathrm{m}^{2}\right)$ & $\left(\mathrm{mJ} / \mathrm{m}^{2}\right)$ \\
\hline 153 & 23.2 & 65.8 & 11.8 & 2.4 & 53.9 & 14.9 & 1.2 \\
\hline 170 & 21.0 & 67.3 & 10.3 & 2.3 & 55.1 & 13.1 & 1.2 \\
\hline 180 & 19.0 & 68.6 & 9.1 & 2.1 & 56.7 & 11.5 & 1.1 \\
\hline
\end{tabular}

determine the surface energy of the nanoparticles (Table S1). The surface of silicon has a natural oxide layer that makes it chemically identical to silica. The same surface can be modified with different silanes or polymers to study the contact angle and wetting properties of the corresponding particles $[22,40]$.

Contact angle and pendant drop measurements at high temperature were carried as described previously $[20,41]$. As shown in Table 2, at high temperatures, the silicon-APTES contact angle is lower than the unmodified one, showing more compatibility and affinity between nanoparticles and PLA. Both modified and unmodified silicon samples show a slight increase in contact angle with an increase in temperature possibly due to different thermal coefficients for surface tension and surface energy (Fig. S2). Based on surface tension measurement of the PLA melt at high temperatures presented in Fig. S1 and the contact angle measurement in Fig. S2, one can measure the work of adhesion via Young-Dupre's equation. The calculated work of adhesion (Fig. 2) for surface modified nanoparticles is higher than the unmodified one, showing better interaction between the APTES-modified silica and PLA. Nanoparticles with lower surface energy and higher work of adhesion result in higher levels of dispersion. Acquiring higher dispersion is a key step to practically achieve the desired properties of the composite. In the case of nanoparticles as nucleating agents in crystallization, a better dispersion means more individual nucleating sites across the matrices [42].

\subsection{Isothermal and non-isothermal melt crystallization of nanocomposites}

The non-isothermal thermal plots of PLA and PLA silica

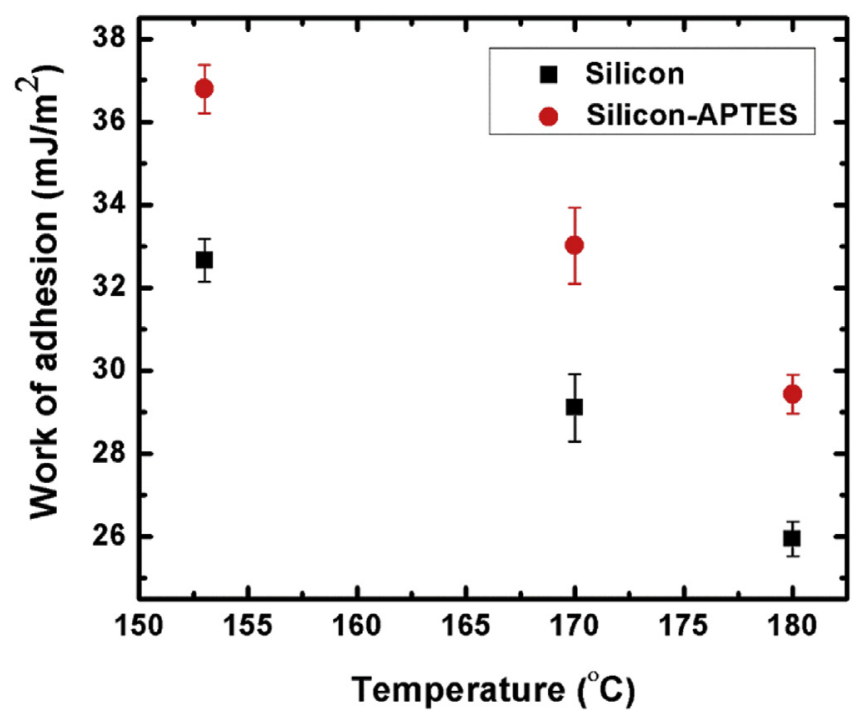

Fig. 2. Work of adhesion between PLA and silicon and silicon-APTES surfaces as representatives of silica and silica-APTES nanoparticle surfaces.

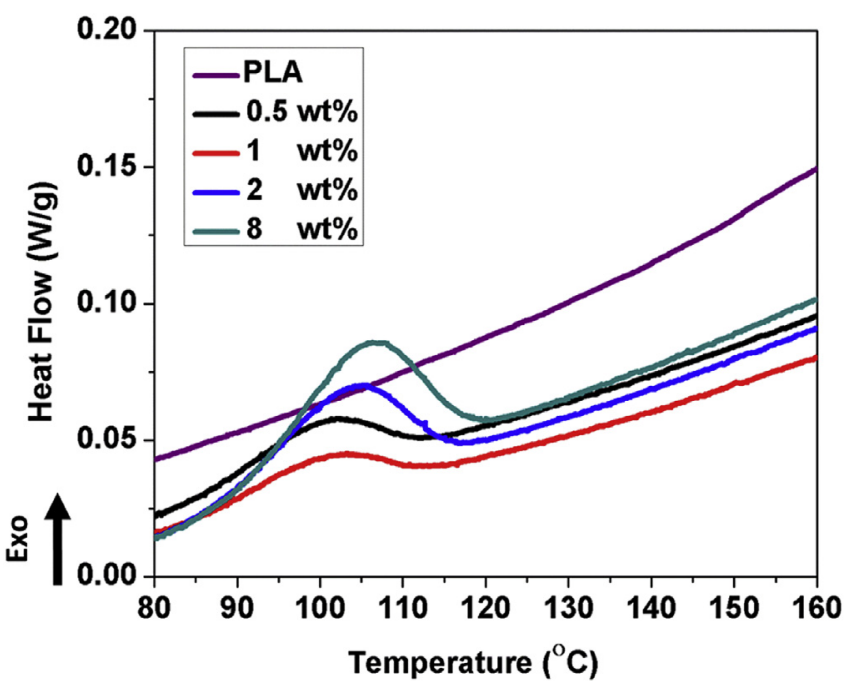

Fig. 3. Cooling segment of non-isothermal thermal analysis of PLA and its silica nanocomposites obtained at atmospheric pressure with $2{ }^{\circ} \mathrm{C} / \mathrm{min}$ cooling rate (peaks are exothermic).

nanocomposites are shown in Fig. 3. Cooling graphs were obtained at a $2{ }^{\circ} \mathrm{C} / \mathrm{min}$ cooling rate at atmospheric pressure. The corresponding thermal properties are also shown in Table 3. Although it underwent cold-crystallization and the subsequently formed crystals were melted, there is no detectable peak for virgin PLA during the cooling section. In PLA 2002D, the melting peak appeared only during the second heating of a heat/cool/heat cycle as a result of cold-crystallization caused by rearrangement of polymer chains upon heating. The slow crystallization kinetics of the 2002D PLA samples is a result of their high D-content and high molecular weight $[43,44]$. Even at low cooling rates, the time necessary for polymer chain rearrangement and reorientation is longer than the time required for measurement. In other words, stable nuclei cannot be formed at fast cooling rates and at higher temperatures [45]. This problem also arises when there is a large amount of co-monomers that possess different stereochemistry [44]. Only after rearrangement during cooling and the availability of more activation energy during heating does the material show cold-crystallization, and consequently, a melting peak. At higher cooling and heating rates $\left(10^{\circ} \mathrm{C} / \mathrm{min}\right)$, both cold-crystallization and melting peaks are barely detectable for PLA 2002D. However, after

Table 3

Summary of non-isothermal analysis of PLA and PLA-silica nanocomposites.

\begin{tabular}{llcc}
\hline Samples & $\mathrm{T}_{\mathrm{c}}\left({ }^{\circ} \mathrm{C}\right)$ & $\Delta \mathrm{H}_{\mathrm{c}}(\mathrm{J} / \mathrm{g})$ & Crystallinity \% \\
\hline PLA 2002D & - & - & - \\
$0.5 \mathrm{wt} \%$ & 101 & 9 & 10 \\
$1 \mathrm{wt} \%$ & 101 & 8 & 9 \\
$2 \mathrm{wt} \%$ & 104 & 18 & 19 \\
$8 \mathrm{wt} \%$ & 107 & 23 & 25 \\
\hline
\end{tabular}




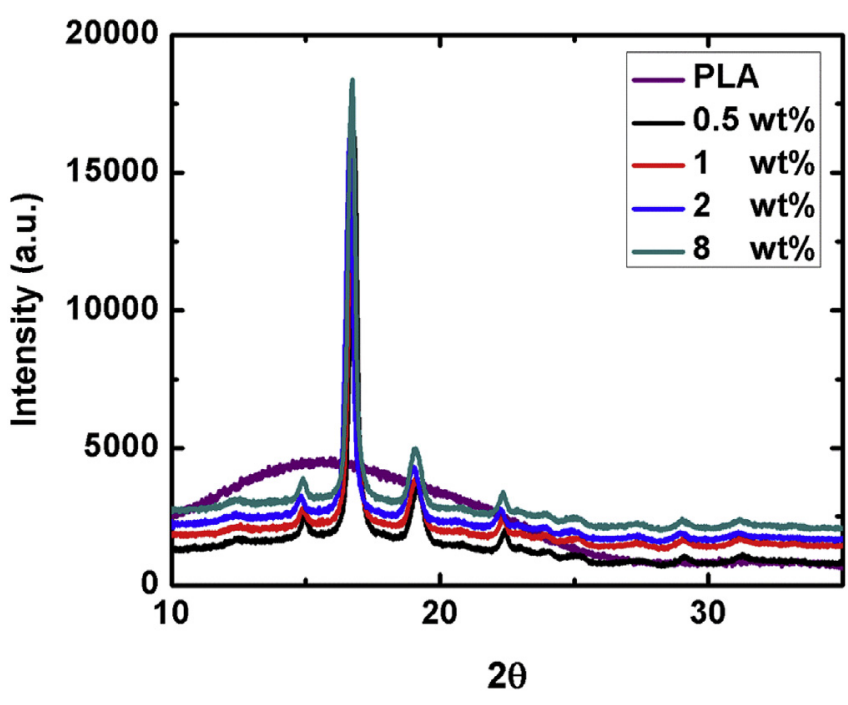

Fig. 4. Wide-angle X-ray diffraction (WAXD) patterns of PLA and its corresponding silica nanocomposites.

the incorporation of only a small amount of surface modified silica nanoparticles (0.5 wt\%), a significant change in crystallization behavior of PLA can be observed; exothermic crystallization peaks appear at temperatures between 100 and $107{ }^{\circ} \mathrm{C}$ for different loadings of silica. Both polymer/nanoparticles interaction and the existence of a crystallographic relationships between the filler and the polymer crystalline structure could be the reason for the observed nucleating effect of the modified silica nanoparticles [46]. An increase in the amount of silica nanoparticles leads to an increase in both crystallization temperature and heat of crystallization up to $107{ }^{\circ} \mathrm{C}$ and $23 \mathrm{~J} / \mathrm{g}$, respectively. The shifts to higher crystallization temperatures by the presence of surface modified silica indicate an acceleration in the overall PLA crystallization [47]. Fig. 4 shows the wide-angle XRD patterns of PLA and PLA silica nanocomposites. For the virgin PLA, there is no distinct peak, and only a wide peak can be seen while all the nanocomposites show $\alpha$ type crystal structure with orthorhombic unit cells with diffraction peaks at $2 \theta=16.8,19.2$, and $22.3^{\circ}$ corresponding to (110), (203) and (205) crystal planes $[7,48,49]$. The intensity of $\alpha$ peaks is nearly constant with an increase in the amount of silica nanoparticles.

Isothermal analysis has been performed at temperatures in the range of non-isothermal crystallization peaks. Two temperatures, 102 and $110^{\circ} \mathrm{C}$, were selected based on the crystallization peaks of the non-isothermal curves. As expected, there was no peak for PLA. However, from Fig. 5 one can observe that after the incorporation of $0.5 \mathrm{wt} \%$ surface-modified silica nanoparticles, the isothermal peak appears with crystallization half-times of 12.5 and 9.2 min for 102 and $110{ }^{\circ} \mathrm{C}$, respectively. As a general trend for the isothermal curves at both temperatures, the half-time decreases with an increase in the amount of surface modified silica nanoparticles [7,50].

\subsubsection{Comparison of nucleation rate in pure matrix and} nanocomposite based on Hoffman-Lauritzen nucleation theory

The Hoffman-Lauritzen nucleation theory is used to show the effect of the nanoparticles and their surface modification on crystallization nucleation. Hoffman et al. [51] developed a model to a)

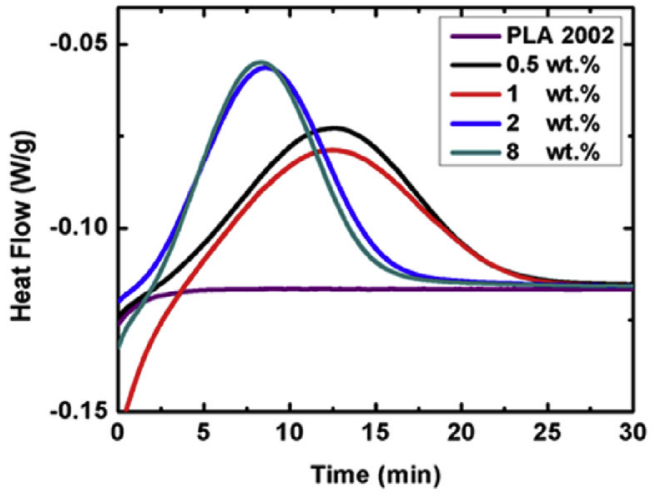

C)

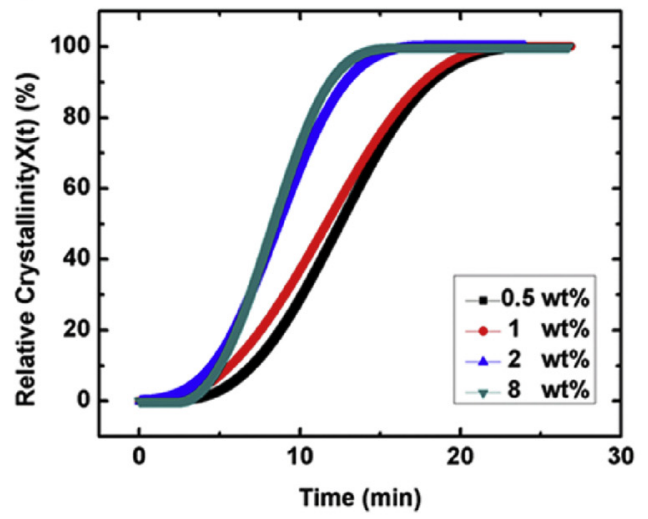

b)

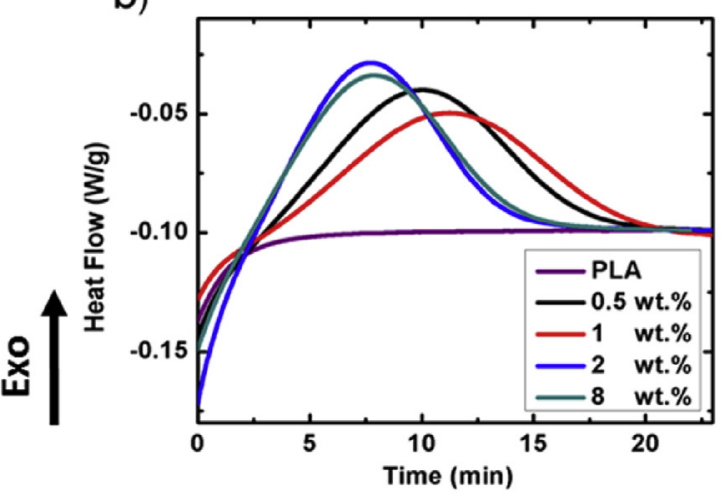

d)

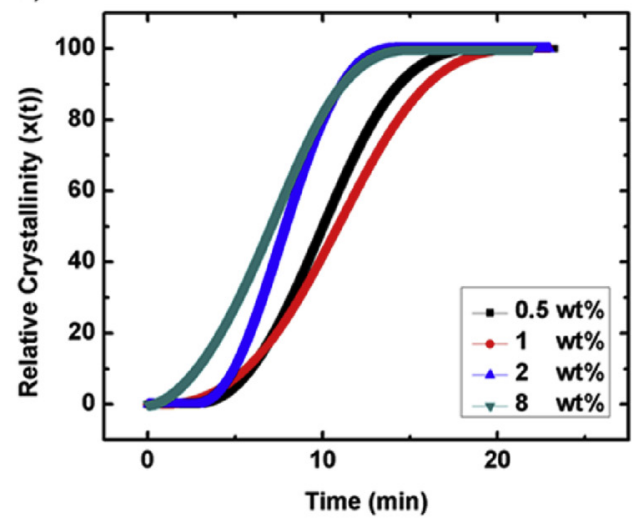

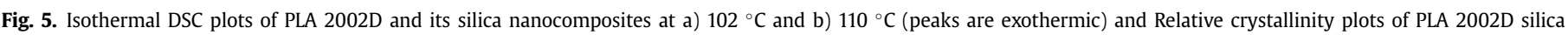
nanocomposites at c) $102{ }^{\circ} \mathrm{C}$ and d) $110^{\circ} \mathrm{C}$. 

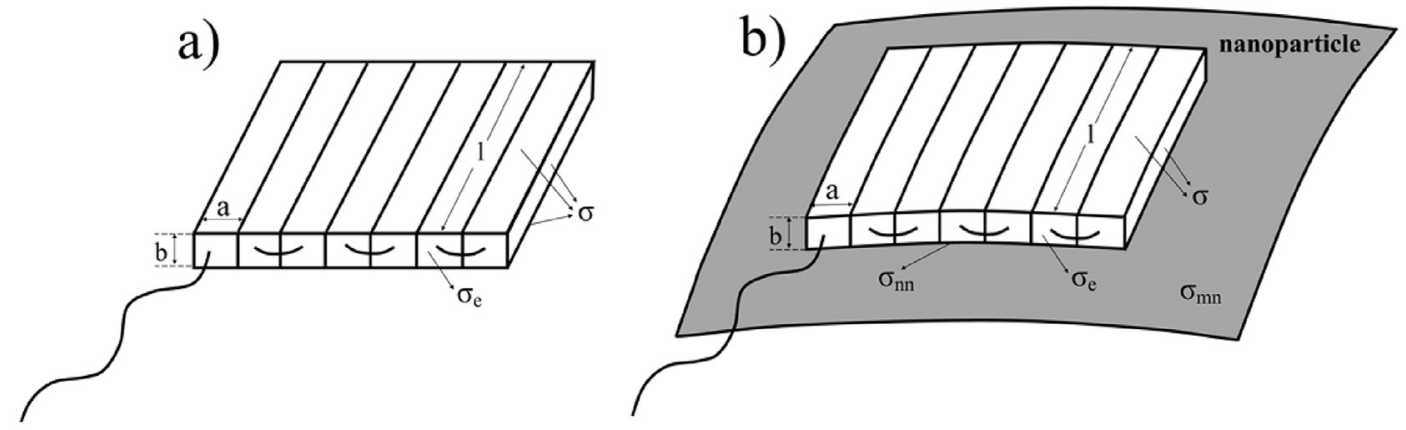

Scheme 1. Schematic representation of a nucleus: a) inside the matrix of a nanocomposite or in pure polymer; b) on the surface of a nanoparticle.

investigate the steady state nucleation rate in crystallization rate of polymers.

$$
I=I_{o} \exp \left(-\frac{U^{*}}{k\left(T-T_{\infty}\right)}\right) \exp \left(-\frac{\Delta \varphi^{*}}{k T}\right)
$$

where $U^{*}$ is the activation energy for reptational diffusion, $T$ is the absolute temperature, $\Delta \varphi^{*}$ is the free energy of formation of a nucleus of critical size, and $k$ is the Boltzmann constant. $T_{\infty}$ is the temperature at which all the motions associated with viscous flow stop, and is related to the glass transition temperature of the polymer. The $\Delta \varphi^{*}$ term in equation (5) is defined as follows:

$\Delta \varphi^{*}=2 \nu a b \sigma_{e}+2 \nu a l \sigma+2 b l \sigma-\nu a b l(\Delta f)$

where $a, b$, and $l$ are width, thickness and length of a stem and a nucleus is composed of $\nu$ stems. $\sigma$ and $\sigma_{e}$ are lateral and fold surface

Table 4

Avrami exponent, kinetic constant, half-time, and crystallization rate of the PLA2002D silica nanocomposites at 102 and $110{ }^{\circ} \mathrm{C}$.

\begin{tabular}{llllll}
\hline Sample & Temperature $\left({ }^{\circ} \mathrm{C}\right)$ & $\mathrm{n}$ & $\mathrm{k}$ & $\mathrm{t}_{1 / 2}(\mathrm{~min})$ & $\mathrm{G}\left(\mathrm{min}^{-1}\right)$ \\
\hline $0.5 \mathrm{wt} \%$ & 102 & 3.15 & 1.04 & 12.5 & 0.080 \\
$1 \mathrm{wt} \%$ & & 4.64 & 0.75 & 10.8 & 0.092 \\
$2 \mathrm{wt} \%$ & & 3.17 & 1.06 & 9.4 & 0.106 \\
$8 \mathrm{wt} \%$ & & 3.63 & 2.77 & 8.4 & 0.119 \\
$0.5 \mathrm{wt} \%$ & \multirow{2}{*}{110} & 2.57 & 1.52 & 9.2 & 0.108 \\
$1 \mathrm{wt} \%$ & & 2.36 & 1.27 & 10.2 & 0.098 \\
$2 \mathrm{wt} \%$ & & 2.29 & 2.60 & 7.2 & 0.138 \\
$8 \mathrm{wt} \%$ & & 2.62 & 2.50 & 6.6 & 0.151 \\
\hline
\end{tabular}

a)

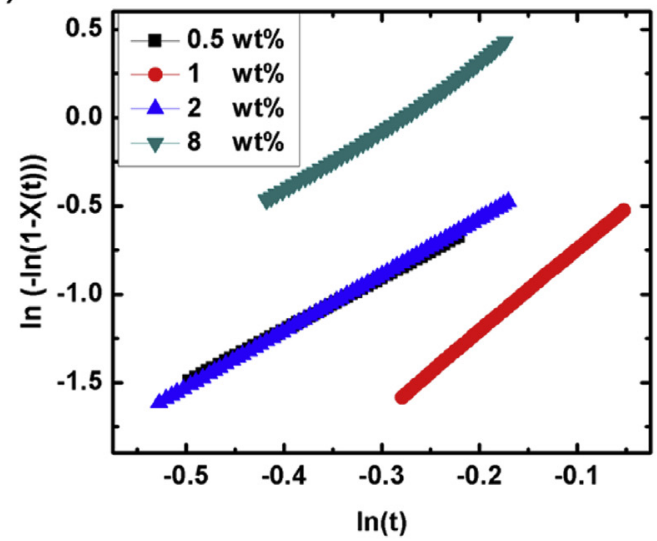

free energies of nucleus, respectively. $\Delta f$ is the bulk free energy of fusion.

As it can be observed in equation (6), only the polymer bulk properties define the free energy of nucleus formation. As illustrated in Scheme 1, the free energy of formation of a nucleus starting from the surface of a nanoparticle is different from a nucleus starting inside the matrix of a polymer [52]. The free energy of formation of a nucleus in presence of a nanoparticle can be written as:

$\Delta \varphi_{\text {nano }}^{*}=2 \nu a b \sigma_{e}+\nu a l\left(\sigma+\sigma_{n n}-\sigma_{m n}\right)+2 b l \sigma-\nu a b l(\Delta f)$

where $\sigma_{m n}$ is the melt-nanoparticle interfacial energy and $\sigma_{n n}$ the nucleus-nanoparticle interfacial energy.

Derivation of the free energy of nucleation with respect to the nucleus dimensions results to a set of equations for each scenario (with or without nanoparticles). Solving the equations leads to obtaining the critical dimensions of the nucleus $\left(a^{*}, b^{*}\right.$, and $\left.l^{*}\right)$. The $\Delta \varphi^{*}$ for both cases are developed and used to find the nucleation rate of both nuclei starting from the surface of nanoparticles and starting inside the matrix of pure polymer as follows:

$$
\begin{aligned}
& I=I_{o} \exp \left(-\frac{U^{*}}{k\left(T-T_{\infty}\right)}\right) \exp \left[-\frac{16 \sigma_{e} \sigma}{k T \Delta f^{2}}(2 \sigma)\right] \\
& I_{\text {nano }}=I_{o} \exp \left(-\frac{U^{*}}{k\left(T-T_{\infty}\right)}\right) \exp \left[-\frac{16 \sigma_{e} \sigma}{k T \Delta f^{2}}\left(\sigma+\sigma_{n n}-\sigma_{m n}\right)\right]
\end{aligned}
$$

b)

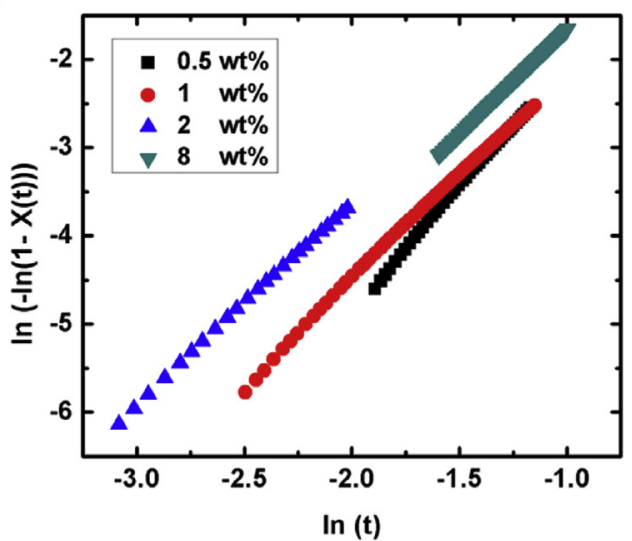

Fig. 6. Avrami double-log plots of PLA2002D silica nanocomposites at a) $102{ }^{\circ} \mathrm{C}$ and b) $110{ }^{\circ} \mathrm{C}$. 
The obtained nucleation rate in presence of a nanoparticle is similar to the case of non-coherent surface nucleation formulated by Hoffman and Lauritzen [52] where non-coherent surface nucleation term was used for molecules with different orientation on the nucleus surface from that of substrate polymer crystal.

Nucleus-nanoparticle interfacial energy is slightly higher that melt-nanoparticle interfacial energy, so $\sigma_{n n}-\sigma_{m n} \approx 0$ and $\sigma$ $\gg\left(\sigma_{n n}-\sigma_{m n}\right)$. Therefore, the second exponential of equation (9) is much larger than the same term in equation (8) leading to the conclusion that the nucleation in the presence of nanoparticle surfaces is much faster and more facile to occur than the pure polymer state (in this specific grade of PLA).

Following the nucleation rate, the rate of crystallization can also be expressed as [51].

$G=G_{o} \exp \left(-\frac{U^{*}}{k\left(T-T_{\infty}\right)}\right) \exp \left[-\frac{4 b \sigma_{e} \sigma}{k T \Delta f}\right]$

where $G_{0}$ is the pre-exponential factor. If the nucleation step is very slow, the required time for start of crystallization would prolong that results in very long crystallization induction time. In the other words, one can say that if the energy barrier for nucleation is significantly high the time scale of this process is too long and consequently no growth happens. Fig. 3 shows that on the time scale of the experiment there is no crystallization occurring in pure polymer while occurrence of crystallization is obvious in all nanocomposite samples. Since there is no difference between the growth rate of pure polymer and nanocomposites (equation (10)), it can be concluded that nucleation is the determining step in crystallization of PLA 2002 and lack of nucleation prevent the crystallization in the time scale of calorimetry experiment. Modified Hoffman-Lauritzen nucleation theory for the nanocomposites justifies the facilitation of the nucleation and consequently the occurrence of crystallization.

\subsubsection{Investigation of the crystallization mechanism by the Avrami equation}

Isothermal analysis based on the Avrami equation [30,31] was performed to investigate the kinetics of crystallization. Although the Avrami equation represents the initial section of polymer crystallization correctly, its exponent can provide valuable information about the crystallization behavior of polymers [32]. The relative crystallinity curves of the nanocomposites in two different temperatures are shown in Fig. 5. The crystallization half-times obtained from the relative crystallinity curves are summarized in Table 4. The Avrami double-log plots of the nanocomposites in both temperatures are also shown in Fig. 6. As it can be seen, all nanocomposites have an $n$ value (Avrami exponent value) in the range of 3-4 and $2-3$ at 102 and $110{ }^{\circ} \mathrm{C}$, respectively. The low $\mathrm{n}$ values correspond to two dimensional (disc shaped) spherulite growth with predetermined and sporadic mechanisms at the beginning of crystallization respectively, while higher $n$ values are correlated to three-dimensional spherulitic growth with a sporadic or a combination of sporadic and simultaneous nucleation types [32,53]. The results show that in the presence of silica nanoparticles, an increase in temperature pushes the crystallization mechanism for PLA from three-dimensional to two-dimensional spherulitic nucleation and growth. Similar effects were observed due to the plasticizing effect $\mathrm{CO}_{2}$ has on the reorientation of polymer chains to less close-packed planar crystals [54]. The crystallization rates $(G)$ (reciprocal of $t_{1 / 2}$ ) of the nanocomposites are also summarized in Table 4. The crystallization rate increases with an increase in the loading of silica. Furthermore, the nanocomposites show higher crystallization rates at higher temperatures.

\subsection{Effect of carbon dioxide on melt crystallization of nanocomposites}

The isothermal high pressure DSC plots of PLA silica nanocomposites under 15 and 21 bar carbon dioxide are presented in Fig. 7. The crystallization half-time results from high-pressure DSC measurements were also compared with atmospheric pressure in Table 5. As can be observed, the crystallization half-time decreases significantly due to the plasticization effect of $\mathrm{CO}_{2}$ molecules, which in turn causes an increase in the mobility of the polymer chains and a decrease in the energy barrier for crystallization [54]. Based on the Hoffman-Lauritzen nucleation theory, the solubilized $\mathrm{CO}_{2}$ plasticizes the matrix and facilitates the molecular movement that leads to the decrease of energy barrier for reptational diffusion of polymer chain $\left(U^{*}\right)$. On the other hand, application of high pressure increases the melting point and undercooling $(\Delta T)$ according to the Clausius-Clapeyron equation and, consequently, an increase in $\Delta f$ increases the second exponential term in equation (10) and further accelerates the crystallization rate.

In the other words, the activation energy barrier for crystallization comes from the chain energy dissipation which comes as a result of chain retraction and folding [55]. The retraction and folding phenomenon depends on not only the viscosity, but also $\mathrm{CO}_{2}$, which, as a solvent is capable of diluting and plasticizing it $[3,56,57]$. On the other hand, for a polymer chain to retract and fold, it is required to create a new surface while interfacial tension resists against this phenomenon. It has been shown that under a)

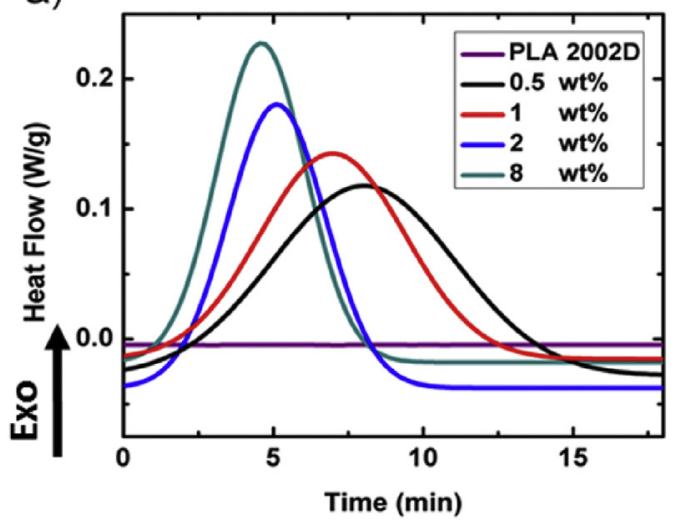

b)

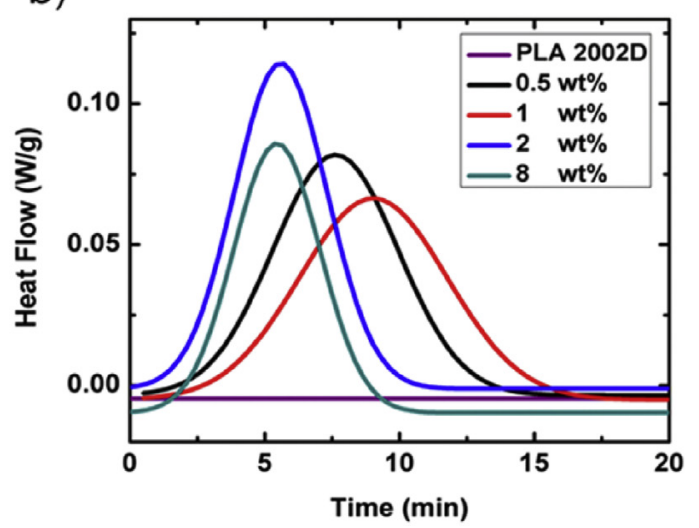

Fig. 7. Isothermal high pressure DSC plots of PLA 2002D and its silica nanocomposites at $102{ }^{\circ} \mathrm{C}$ and a) 15 bar and b) 21 bar (peaks are exothermic). 
Table 5

Comparison between crystallization half-time of silica nanocomposites at three different pressures of carbon dioxide.

\begin{tabular}{llll}
\hline $\mathrm{t}_{1 / 2}(\mathrm{~min})$ & & & \\
\hline Sample & Atmospheric & $15 \mathrm{bar}$ & $21 \mathrm{bar}$ \\
\hline $0.5 \mathrm{wt} \%$ & 12.5 & 7.8 & 7.0 \\
$1 \mathrm{wt} \%$ & 11.7 & 6.5 & 8.5 \\
$2 \mathrm{wt} \%$ & 8.5 & 4.8 & 5.1 \\
$8 \mathrm{wt} \%$ & 8.1 & 4.5 & 5.0 \\
\hline
\end{tabular}

Table 6

Avrami exponent, kinetic constant, half-time, and crystallization rate of the PLA 3001D, 4032D and their silica nanocomposites at 102 and $110{ }^{\circ} \mathrm{C}$.

\begin{tabular}{lllccl}
\hline Sample & Temperature $\left({ }^{\circ} \mathrm{C}\right)$ & $\mathrm{n}$ & $\mathrm{k}$ & $\mathrm{t}_{1 / 2}(\mathrm{~min})$ & $\mathrm{G}\left(\mathrm{min}^{-1}\right)$ \\
\hline 3001D & 102 & 4.2 & 0.41 & 28 & 0.035 \\
3001D-2 wt\% & & 4.09 & 11.04 & 3.5 & 0.285 \\
4032D & & 4.6 & 0.31 & 32 & 0.031 \\
4032D-2 wt\% & & 4.44 & 5.56 & 3.2 & 0.312 \\
3001D & 110 & 4.1 & 0.84 & 31 & 0.032 \\
3001D-2 wt\% & & 3.29 & 11.58 & 3.2 & 0.312 \\
4032D & & 3.27 & 1.08 & 32 & 0.031 \\
4032D-2 wt\% & & 3.5 & 11.16 & 3.5 & 0.285 \\
\hline
\end{tabular}

compressed $\mathrm{CO}_{2}$, the interfacial tension of polymer melts decreases, and by this same effect, compressed $\mathrm{CO}_{2}$ can increase the rate of crystallization by lowering the activation energy associated with it $[20,58]$. As the results show, by further increasing $\mathrm{CO}_{2}$ pressure, the crystallization half-time remains constant or slightly increases. Other studies $[54,59]$ showed an increase in both the total crystallinity and the crystallization rate at pressures of $\mathrm{CO}_{2}$ up to 20 bar.

\subsection{Nanocomposites of different molecular weights and D-contents of PLA}

The effect of nanoparticles on PLA crystallization can be observed more clearly in the 4032D and 3001D grades, which have a lower molecular weight, and less D-content compared to 2002D. As shown in Fig. 8 and Fig. 9, the 3001D and 4032D grades have a very wide peak in the range of $35-40 \mathrm{~min}$ at both 102 and $110{ }^{\circ} \mathrm{C}$. It can be further observed that surface-modified silica nanoparticles accelerate the crystallization process by decreasing the half-time by up to a factor of 10 at both 102 and $110{ }^{\circ} \mathrm{C}$. The observation can be explained in terms of the average isotactic sequence length $\left(\zeta=\frac{a}{X_{D}}\right)$ which is a measure of ordering in PLA chains [7]. Where a is a coefficient that depends on the source of D-lactide units in polymerization feed (here it is equal to 2 ) and $X_{D}$ is the molar fraction of D units. In both 3001D and 4032D polymers the average isotactic sequence length and consequently the chain ordering is high, therefore, the crystallization occurs even though it is very slow compared with their nanocomposites. However, in PLA2002D with lower level of chain order, only with presence of a heterogeneous nucleation (silica nanoparticles in our case), crystallization occurs.

Analysis of the Avrami curves in Figs. 8 and 9 reveals that after incorporation of silica nanoparticles the $n$ value for 3001D and 4032D grades has not changed significantly (see Table 6). In other words, PLA undergoes three-dimensional bulk crystallization before and after the incorporation of nanoparticles [50]. The reason is the dependency of the lamellae growth to the adjacent ones in 3001D and 4032D samples as a result of higher density of

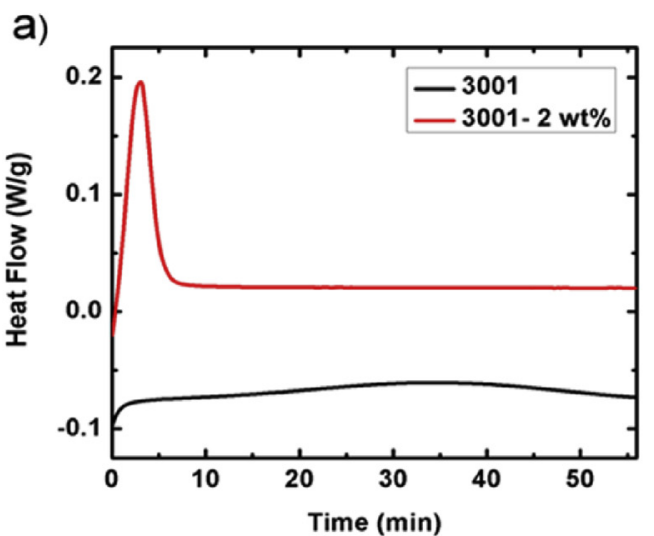

C)

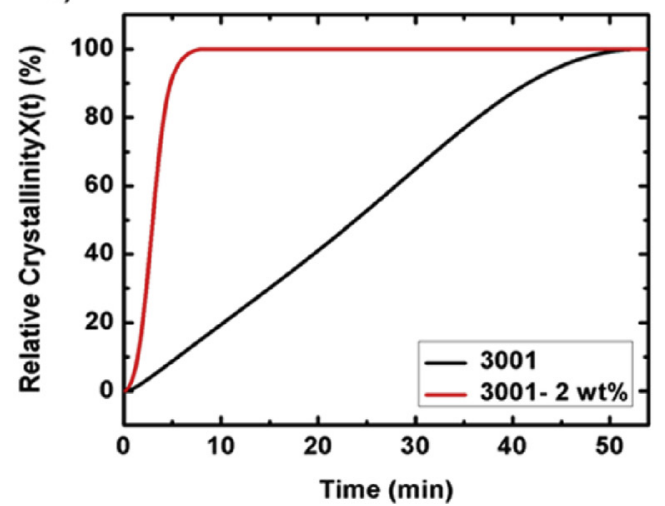

b)

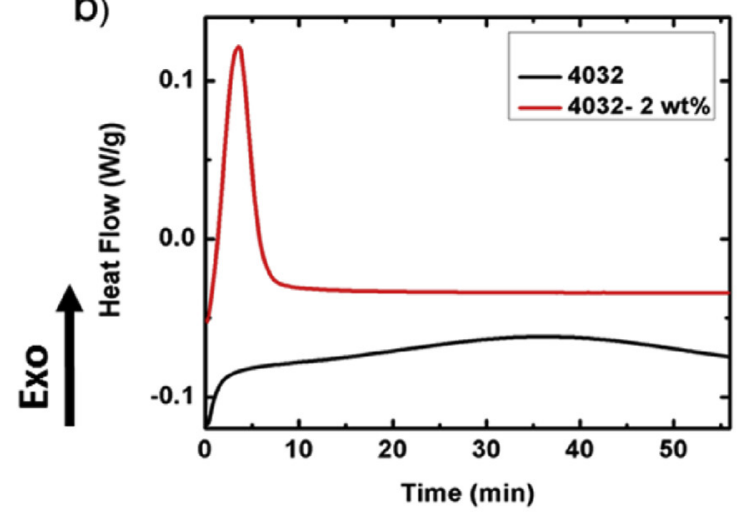

d)

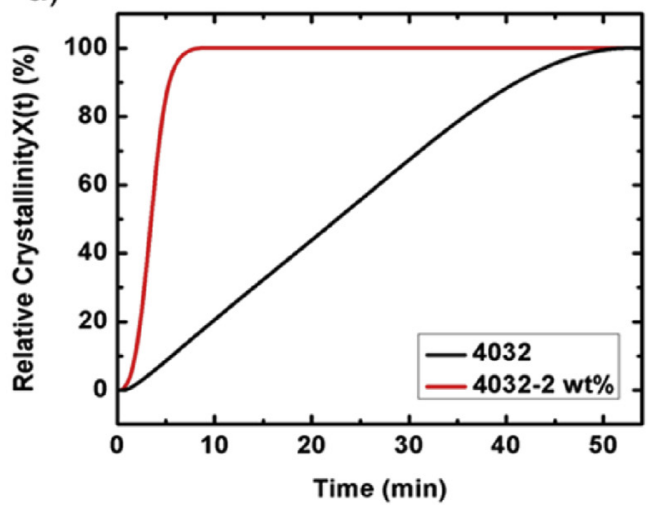

Fig. 8. Isothermal DSC and relative crystallinity plots of PLA 3001D (a and c) and PLA 4032D (b and d) and their silica nanocomposites at 102 ${ }^{\circ} \mathrm{C}$ (peaks are exothermic). 
a)

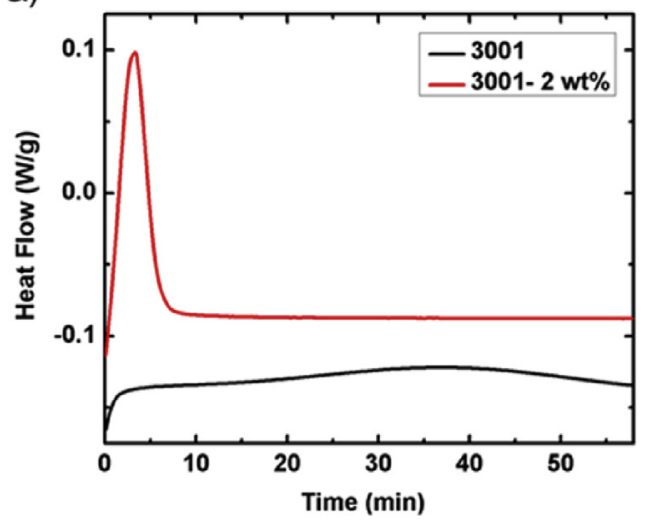

C)

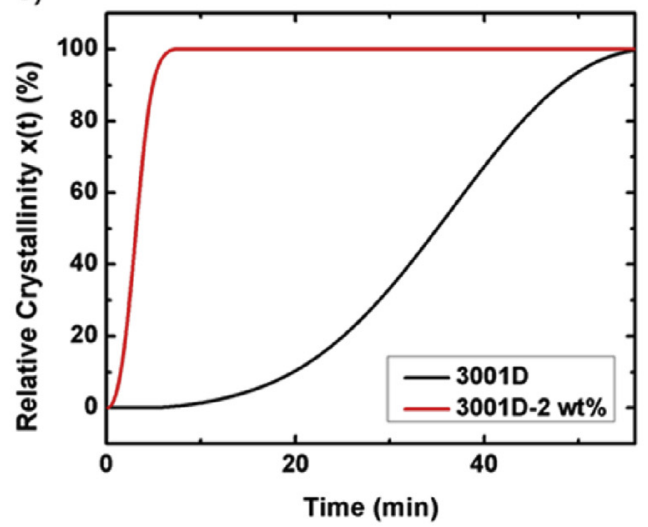

b)

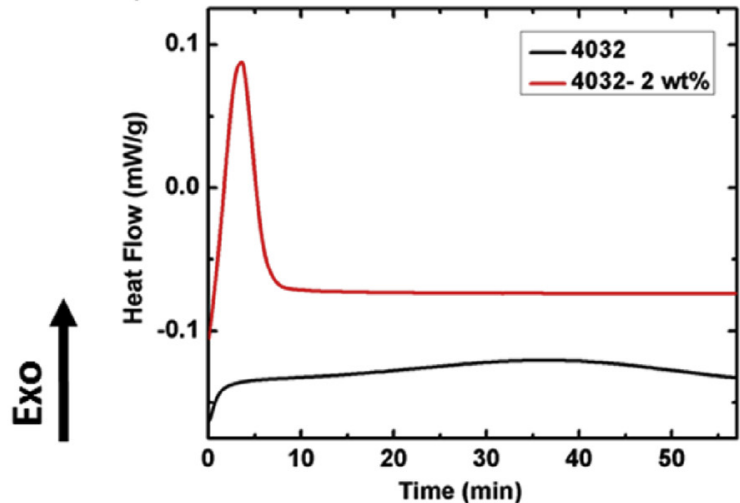

d)

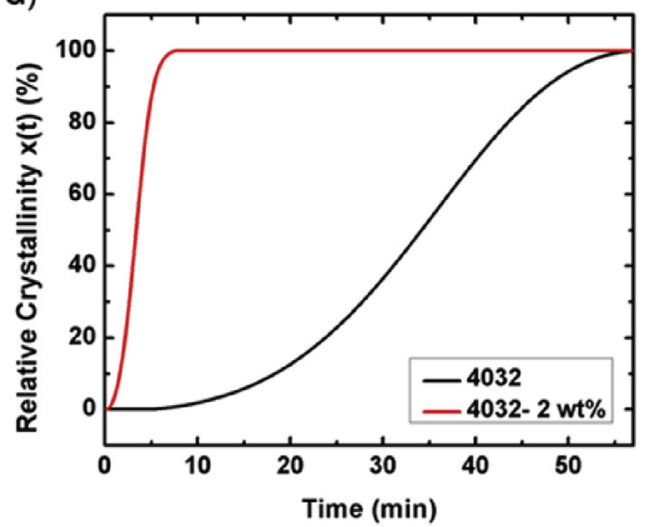

Fig. 9. Isothermal DSC and relative crystallinity plots of PLA 3001D (a and c) and PLA 4032D (b and d) and their silica nanocomposites at $110{ }^{\circ} \mathrm{C}$ (peaks are exothermic).

homogenous and heterogeneous nucleation sites.

\section{Conclusions}

The present study was designed to determine the effect of surface-modified silica nanoparticles on PLA crystallization. Both isothermal and non-isothermal crystallization for various loadings of silica nanoparticles were explored. The results showed a remarkable improvement in crystallization rate and crystallinity for PLA with high molecular weight and D-content. The WAXD patterns of the samples showed the appearance of $\alpha$ type crystal structures with orthorhombic unit cells after the incorporation of surface-modified silica nanoparticles. A modified HoffmanLauritzen nucleation theory justified the acceleration of crystallization by introduction of the surface energy of nanoparticles, interfacial energy between nanoparticle and lateral surface of crystals into the rate equation. Analysis of the Avrami equation showed a three-dimensional spherulitic structure which, at higher temperatures, proceeds towards a two-dimensional structure with less packed crystals. It was shown that the presence of carbon dioxide increases the crystallization rate at 15 bar, but at the higher pressure of 21 bar, the crystallization rate became nearly constant. The crystallization rate of PLA grades with lower molecular weights and lower D-content increased by up to a factor of 10 with no change in crystallization mechanism after the incorporation of surface-modified silica nanoparticles.

\section{Acknowledgments}

The authors acknowledge the financial support of the Natural
Sciences and Engineering Research Council (NSERC) of Canada, Network for Innovative Plastic Materials and Manufacturing Processes (NIPMMP), Ontario Centers of Excellence, and Canada Research Chairs (CRC).

\section{Appendix A. Supplementary data}

Supplementary data related to this article can be found at http:// dx.doi.org/10.1016/j.polymer.2016.06.019.

\section{References}

[1] D. Garlotta, A literature review of poly (lactic acid), J. Polym. Environ. 9 (2001) 63-84, http://dx.doi.org/10.1023/A:1020200822435.

[2] L.-T. Lim, R. Auras, M. Rubino, Processing technologies for poly(lactic acid) Prog. Polym. Sci. 33 (2008) 820-852, http://dx.doi.org/10.1016/ j.progpolymsci.2008.05.004.

[3] R. Auras, B. Harte, S. Selke, An overview of polylactides as packaging materials Macromol. Biosci. 4 (2004) 835-864, http://dx.doi.org/10.1002/ mabi.200400043.

[4] M. Nofar, C.B. Park, Poly (lactic acid) foaming, Prog. Polym. Sci. 39 (2014) 1-21, http://dx.doi.org/10.1016/j.progpolymsci.2014.04.001.

[5] C.J. Weber, V. Haugaard, R. Festersen, G. Bertelsen, Production and applications of biobased packaging materials for the food industry, Food Addit. Contam. 19 (2002) 172-177, http://dx.doi.org/10.1080/02652030110087483.

[6] K. Zhang, A.K. Mohanty, M. Misra, Fully biodegradable and biorenewable ternary blends from polylactide, poly(3-hydroxybutyrate-co-hydroxyvalerate) and poly(butylene succinate) with balanced properties, ACS Appl. Mater. Interfaces 4 (2012) 3091-3101, http://dx.doi.org/10.1021/am3004522.

[7] S. Saeidlou, M. a. Huneault, H. Li, C.B. Park, Poly(lactic acid) crystallization, Prog. Polym. Sci. 37 (2012) 1657-1677, http://dx.doi.org/10.1016/ j.progpolymsci.2012.07.005.

[8] D. Eaves, Handbook of Polymer Foams, Rapra Technology Limited, 2004.

[9] A. Ameli, M. Nofar, D. Jahani, G. Rizvi, C.B. Park, Development of high void fraction polylactide composite foams using injection molding: crystallization 
and foaming behaviors, Chem. Eng. J. 262 (2015) 78-87, http://dx.doi.org/ 10.1016/j.cej.2014.09.087.

[10] C.-Y. Hung, C.-C. Wang, C.-Y. Chen, Enhanced the thermal stability and crystallinity of polylactic acid (PLA) by incorporated reactive PS-b-PMMA-b-PGMA and PS-b-PGMA block copolymers as chain extenders, Polymer 54 (2013) 1860-1866, http://dx.doi.org/10.1016/j.polymer.2013.01.045.

[11] L.-I. Palade, H.J. Lehermeier, J.R. Dorgan, Melt rheology of high l-content poly(lactic acid), Macromolecules 34 (2001) 1384-1390, http://dx.doi.org 10.1021/ma001173b.

[12] S.-Y. Gu, J. Ren, B. Dong, Melt rheology of polylactide/montmorillonite nanocomposites, J. Polym. Sci. Part B Polym. Phys. 45 (2007) 3189-3196, http://dx.doi.org/10.1002/polb.21317.

[13] Y. Di, S. Iannace, E. Di Maio, L. Nicolais, Poly(lactic acid)/organoclay nanocomposites: thermal, rheological properties and foam processing, J. Polym. Sci. Part B Polym. Phys. 43 (2005) 689-698, http://dx.doi.org/10.1002/ polb.20366.

[14] M. Nofar, A. Tabatabaei, C.B. Park, Effects of nano-/micro-sized additives on the crystallization behaviors of PLA and PLA/CO 2 mixtures, Polymer 54 (2013) 2382-2391, http://dx.doi.org/10.1016/j.polymer.2013.02.049.

[15] A. Ameli, D. Jahani, M. Nofar, P.U. Jung, C.B. Park, Processing and characterization of solid and foamed injection-molded polylactide with talc, J. Cell. Plast. Online Ver. (2013) 1-24, http://dx.doi.org/10.1177/ $0021955 X 13481993$.

[16] H. Tsuji, M. Sawada, L. Bouapao, Biodegradable polyesters as crystallizationaccelerating agents of poly(l-lactide), ACS Appl. Mater. Interfaces 1 (2009) 1719-1730, http://dx.doi.org/10.1021/am9002759.

[17] V. Nagarajan, K. Zhang, M. Misra, A.K. Mohanty, Overcoming the fundamental challenges in improving the impact strength and crystallinity of PLA biocomposites: influence of nucleating agent and mold temperature, ACS Appl. Mater. Interfaces 7 (2015) 11203-11214, http://dx.doi.org/10.1021/ acsami.5b01145.

[18] H. Li, M.A. Huneault, Effect of nucleation and plasticization on the crystallization of poly(lactic acid), Polymer 48 (2007) 6855-6866, http://dx.doi.org/ 10.1016/j.polymer.2007.09.020.

[19] R. Androsch, H.M.N. Iqbal, C. Schick, Non-isothermal crystal nucleation of poly (l-lactic acid), Polymer 81 (2015) 151-158, http://dx.doi.org/10.1016/ j.polymer.2015.11.006.

[20] K. Sarikhani, K. Jeddi, R.B. Thompson, C.B. Park, P. Chen, Effect of pressure and temperature on interfacial tension of poly lactic acid melt in supercritical carbon dioxide, Thermochim. Acta 609 (2015) 1-6, http://dx.doi.org/10.1016/ j.tca.2015.04.005.

[21] S.H. Mahmood, A. Ameli, N. Hossieny, C.B. Park, The interfacial tension of molten polylactide in supercritical carbon dioxide, J. Chem. Thermodyn. 75 (2014) 69-76, http://dx.doi.org/10.1016/j.jct.2014.02.017.

[22] K. Sarikhani, K. Jeddi, R.B. Thompson, C.B. Park, P. Chen, Adsorption of surfacemodified silica nanoparticles to the interface of melt poly(lactic acid) and supercritical carbon dioxide, Langmuir 31 (2015) 5571-5579, http:// dx.doi.org/10.1021/acs.langmuir.5b00306.

[23] A. Wong, S.F.L. Wijnands, T. Kuboki, C.B. Park, Mechanisms of nanoclayenhanced plastic foaming processes: effects of nanoclay intercalation and exfoliation, J. Nanoparticle Res. 15 (2013), http://dx.doi.org/10.1007/s11051013-1815-y.

[24] S.N. Leung, A. Wong, L.C. Wang, C.B. Park, Mechanism of extensional stressinduced cell formation in polymeric foaming processes with the presence of nucleating agents, J. Supercrit. Fluids 63 (2012) 187-198, http://dx.doi.org 10.1016/j.supflu.2011.12.018.

[25] G.Z. Papageorgiou, D.S. Achilias, D.N. Bikiaris, G.P. Karayannidis, Crystallization kinetics and nucleation activity of filler in polypropylene/surface-treated SiO2 nanocomposites, Thermochim. Acta 427 (2005) 117-128, http:/ dx.doi.org/10.1016/j.tca.2004.09.001.

[26] O.C. Wokadala, S.S. Ray, J. Bandyopadhyay, J. Wesley-Smith, N.M. Emmambux, Morphology, thermal properties and crystallization kinetics of ternary blends of the polylactide and starch biopolymers and nanoclay: the role of nanoclay hydrophobicity, Polymer 71 (2015) 82-92, http://dx.doi.org/10.1016 j.polymer.2015.06.058.

[27] W. Stober, Controlled growth of monodisperse silica spheres in the micron size range*1, J. Colloid Interface Sci. 26 (1968) 62-69, http://dx.doi.org/ 10.1016/0021-9797(68)90272-5.

[28] D. Nyström, P. Antoni, E. Malmström, M. Johansson, M. Whittaker, A. Hult, Highly-ordered hybrid organic-inorganic isoporous membranes from polymer modified nanoparticles, Macromol. Rapid Commun. 26 (2005) 524-528 http://dx.doi.org/10.1002/marc.200400617.

[29] E.T. Vandenberg, L. Bertilsson, B. Liedberg, K. Uvdal, R. Erlandsson, H. Elwing, et al., Structure of 3-aminopropyl triethoxy silane on silicon oxide, J. Colloid Interface Sci. 147 (1991) 103-118, http://dx.doi.org/10.1016/0021-9797(91) 90139-Y.

[30] M. Avrami, Kinetics of phase change. I General theory, J. Chem. Phys. 7 (1939) 1103, http://dx.doi.org/10.1063/1.1750380.

[31] M. Avrami, Kinetics of phase change. II - transformation-time relations for random distribution of nuclei, J. Chem. Phys. 8 (1940) 212-224, http:/ dx.doi.org/10.1063/1.1750631.

[32] L.H. Sperling, Introduction to Physical Polymer Science, 2005, http:// dx.doi.org/10.1002/0471757128.
[33] B. Wunderlich, Macromolecular physics, in: Macromol. Phys., Vol 2, 1980, http://dx.doi.org/10.1002/crat.19770120121.

[34] K.S. Kim, H.M. Lee, I.S. Youn, M. Saleh, J.W. Lee, Interactions of CO2 with various functional molecules, Phys. Chem. Chem. Phys. 17 (2015) 10925-10933, http://dx.doi.org/10.1039/C5CP00673B.

[35] G.P. Knowles, J.V. Graham, S.W. Delaney, A.L. Chaffee, Aminopropyl-functionalized mesoporous silicas as $\mathrm{CO} 2$ adsorbents, Fuel Process. Technol. 86 (2005) 1435-1448, http://dx.doi.org/10.1016/j.fuproc.2005.01.014.

[36] S.N. Leung, C.B. Park, H. Li, Numerical simulation of polymeric foaming processes using modified nucleation theory, Plast. Rubber Compos. 35 (2006) 93-100, http://dx.doi.org/10.1179/174328906X103079.

[37] P. Wilt, Nucleation rates and bubble stability in water-carbon dioxide solutions, J. Colloid Interface Sci. 112 (1986) 530-538, http://dx.doi.org/10.1016/ 0021-9797(86)90122-0.

[38] J.C. Fisher, The fracture of liquids, J. Appl. Phys. 19 (1948) 1062-1067, http:// dx.doi.org/10.1063/1.1698012.

[39] Y. Chevalier, M.A. Bolzinger, Emulsions stabilized with solid nanoparticles: pickering emulsions, Colloids Surfaces A Physicochem. Eng. Asp. 439 (2013) 23-34, http://dx.doi.org/10.1016/j.colsurfa.2013.02.054.

[40] K. Matyjaszewski, D. Hongchen, W. Jakubowski, J. Pietrasik, A. Kusumo, Grafting from surfaces for "everyone": ARGET ATRP in the presence of air, Langmuir 23 (2007) 4528-4531, http://dx.doi.org/10.1021/la063402e.

[41] H. Park, C.B. Park, C. Tzoganakis, K.H. Tan, P. Chen, Surface tension measurement of polystyrene melts in supercritical carbon dioxide, Ind. Eng. Chem. Res. 45 (2006) 1650-1658.

[42] B. Nagendra, K. Mohan, E.B. Gowd, Polypropylene/Layered double hydroxide (LDH) nanocomposites: influence of LDH particle size on the crystallization behavior of polypropylene, ACS Appl. Mater. Interfaces 7 (2015) 12399-12410, http://dx.doi.org/10.1021/am5075826.

[43] J. Huang, M.S. Lisowski, J. Runt, E.S. Hall, R.T. Kean, N. Buehler, et al., Crystallization and microstructure of poly(L-lactide-co-meso-lactide) copolymers, Macromolecules 31 (1998) 2593-2599, http://dx.doi.org/10.1021/ ma9714629.

[44] S. Baratian, E.S. Hall, JS, Lin, R. Xu, J. Runt, Crystallization and solid-state structure of random polylactide copolymers: poly(L-lactide-co-D-lactide)s, Macromolecules 34 (2001) 4857-4864, http://dx.doi.org/10.1021/ ma001125r.

[45] L.C. López, G.L. Wilkes, Crystallization kinetics of poly(p-phenylene sulphide): effect of molecular weight, Polymer 29 (1988) 106-113, http://dx.doi.org/ 10.1016/0032-3861(88)90207-8.

[46] S. Ouchiar, G. Stoclet, C. Cabaret, V. Gloaguen, Influence of the filler nature on the crystalline structure of polylactide-based nanocomposites: new insights into the nucleating effect, Macromolecules 49 (2016) (2016) 2782-2790, http://dx.doi.org/10.1021/acs.macromol.5b02746.

[47] H. Tsuji, H. Takai, N. Fukuda, H. Takikawa, Non-isothermal crystallization behavior of poly(l-lactic acid) in the presence of various additives, Macromol. Mater. Eng. 291 (2006) 325-335, http://dx.doi.org/10.1002/ mame.200500371.

[48] P. De Santis, A.J. Kovacs, Molecular conformation of poly(S-lactic acid), Biopolymers 6 (1968) 299-306, http://dx.doi.org/10.1002/bip.1968.360060305.

[49] C.W. Z.Su, Y.Liu, W.Guo, Q Li, crystallization behavior of poly(Lactic acid) filled with modified carbon black, J. Macromol. Sci. Part B phys. 48 (n.d.) 670-683. doi:http://dx.doi.org/10.1080/00222340902837238.

[50] M. Nofar, A. Tabatabaei, C.B. Park, Effects of nano-/micro-sized additives on the crystallization behaviors of PLA and PLA/CO2 mixtures, Polymer 54 (2013) 2382-2391, http://dx.doi.org/10.1016/j.polymer.2013.02.049.

[51] N. Hannay (Ed.), Treatise on Solid State Chemistry, 1976, p. 497, http:// dx.doi.org/10.1007/978-1-4684-2664-9.

[52] J.D. Hoffman, J.I. Lauritzen, Crystallization of bulk polymers with chain folding: theory of growth of lamellar spherulites, J. Res. Natl. Bur. Stand. A. Phys. Chem. 65 (1961) 1961, http://dx.doi.org/10.6028/jres.065A.035.

[53] J.D. Hoffman, J.I. Lauritzen, Crystallization of bulk polymers with chain folding: theory of growth of lamellar spherulites, J. Res. Natl. Bur. Stand. A. Phys. Chem. 65 (1961) 1961, http://dx.doi.org/10.6028/jres.065A.035.

[54] M. Nofar, W. Zhu, C.B. Park, Effect of dissolved $\mathrm{CO}_{2}$ on the crystallization behavior of linear and branched PLA, Polymer 53 (2012) 3341-3353, http:// dx.doi.org/10.1016/j.polymer.2012.04.054.

[55] D. Li, T. Liu, L. Zhao, X. Lian, W. Yuan, Foaming of poly(lactic acid) based on its nonisothermal crystallization behavior under compressed carbon dioxide, Ind. Eng. Chem. Res. 50 (2011) 1997-2007, http://dx.doi.org/10.1021/ie101723g.

[56] Z. Zhang, Y.P. Handa, An in situ study of plasticization of polymers by highpressure gases, J. Polym. Sci. 36 (1998) 977-982, http://dx.doi.org/10.1002/ (sici)1099-0488(19980430)36:6<977::aid-polb5>3.0.co;2-d.

[57] T.S. Chow, Molecular Interpretation of the glass transition temperature of polymer-diluent systems, Macromolecules 13 (1980) 362-364, http:// dx.doi.org/10.1021/ma60074a029.

[58] X. Liao, Y.G. Li, C.B. Park, P. Chen, Interfacial tension of linear and branched PP in supercritical carbon dioxide, J. Supercrit. Fluids 55 (2010) 386-394, http:// dx.doi.org/10.1016/j.supflu.2010.06.011.

[59] M. Takada, S. Hasegawa, M. Ohshima, Crystallization kinetics of poly(L-lactide) in contact with pressurized CO2, Polym. Eng. Sci. 44 (2004) 186-196, http:// dx.doi.org/10.1002/pen.20017. 